\title{
Resonance Method of Detection and Neutralization of Covid-19
}

\author{
Evgeny Bryndin*
}

Department of Research Centre "NATURE INFORMATIC" of Technological Platform Future Medicine, Novosibirsk, Russia

*Corresponding author: Evgeny Bryndin, Department of Research Centre "NATURE INFORMATIC" of Technological Platform Future Medicine, Novosibirsk, Russia

\section{Abstract}

The person is difficult essence which unites a body, reason, soul and spirit. The spirit is the highest beginning in the person. It is connected with conscience - an internal criterion of justice, honesty, kindness, a righteousness. Thin material soul is connected with feelings and desires. The reason is connected with knowledge and thinking. The person is connected with the inner and physical world. It is connected by spirit and soul with an inner world, either light kind, or dark angry. Light cheerful he unites to Divine Spirit. Lives in a material world of people a body. The soul connects human lives in these worlds, connecting mind and body. The reason, spirit, soul and body influence at each other. Thoughts, feelings, desires and emotions create our body. Just thoughts, good wishes support normal functioning of an organism at all levels. No just thoughts, evil desires break normal functioning of an organism at all levels. The human body represents an oscillatory contour. In a physical body there is a difficult, combined, hierarchical, volume system of the connected standing waves of various quality: electric, magnetic, thermal, light, gravitational, mental.

Electromagnetic standing waves form the biofield providing an electromagnetic homeostasis. Source of electromagnetic oscillations are cages. Development of an organism goes under the influence of mental energy. Mental energy gets into all cages. The biochemical carrier of mental energy are structural components of a cover of nervous fibers of the lipidic nature. Mental energy influences an electromagnetic homeostasis. Quality of mental energy depends on consciousness, feelings and desires. Arriving justly on conscience, the person produces mental energy of tranquility, which provides an electromagnetic homeostasis, differently mental energy of frustration which breaks an electromagnetic homeostasis is produced. In article is considered spiritual needs of the person as fruits of opposition of infection with COVID-19 coronavirus. A resonant approach to the detection of coronavirus COVID-19 is also proposed.

Keywords: COVID-19 coronavirus; Vibration approach; Microdevice; Resonance; Own frequency.

\section{Introduction}

In 2020, the Sun is at a minimum of the 24th cycle, during such periods, ultraviolet radiation, which is an excellent disinfectant, is sharply reduced, therefore, conditions are created for the growth and spread of bacteria. The Serbian scientist explains the pandemic of the coronavour precisely this factor. Satellite images show that the radiation of the Sun at the time of the appearance of coronavirus was weaker than during the period of H1N1 spread. In 2009, the ultraviolet level was eight units, and in 2019 - only five units. Researchers from the United States and Brazil have also previously concluded that the mortality rate from diseases may depend on solar activity. And this connection turned out to be stronger than they expected. Radiation consists of charged elementary particles, mainly protons, which move at the speed of light. When they encounter gas molecules in the Earth's atmosphere, an additional cascade of spatial radiation is created that can penetrate materials, including into the human body. Causing profound changes in the nucleic acid structure of viruses, ultraviolet rays do not significantly affect the protein envelope, as a result of which inactivated viruses are able to maintain their antigenic and immunogenic activity. The sun in the minimum quartz virus like SARS/MERS is not enough, and it continues to live. Ultraviolet light (UV-C) with a wavelength of 100-280 nanometers destroys the pathogen COVID-19. The discovery belongs to scientists at Boston University, USA, who used Signify disinfectant lamps in their study. 
The so-called far ultraviolet, or UV-C, does not pass through the Earth's ozone layer, and it is also blocked by oxygen in the atmosphere. It also filters out most of the average ultraviolet (UV-B rays). Thus, only the near ultraviolet (UV-A) and part of the middle ultraviolet (UVB) reach the surface of the Earth. It has long been known that UV-C rays have bactericidal effects. There are several lamps on the market that clean the surfaces of viruses and pathogens in laboratories and in the food industry with the help of such radiation. Also, such light saves water from organic pollutants.

Tried to process the samples containing SARS-CoV-2 coronavirus by means of ultra-violet lamps. It was such an experiment conducted by scientists from the United States. During it, they used Signify's ultraviolet lamps of the TUV series with a capacity of 35 watts, generating radiation at a wavelength of 254 nanometers. It turned out that lamps generating UV-C rays destroy $96 \%$ of viral particles within three seconds. This suggests that in 25 seconds of exposure with a certain power $(22 \mathrm{~mJ} / \mathrm{cm} 2)$ 99.9999\% of pathogenic particles will be destroyed. As experts explain, ultraviolet radiation in this case destroys the genetic material of the virus, depriving it of the ability to infect the cell and continue to exist.

Our body is 90 percent water. So with the help of water, changing its properties, you can affect the "covid - 19," in terms of its neutralization. These are the frequencies that structure the water. Water acquires properties according to which, in such water, the virus dies. Along this path - changes in the properties of water, the Japanese researcher Masaru Emoto has already passed. It frozen water with symmetric crystallization. In thawed meltwater, the virus dies.

Various approaches to the detection and neutralization of coronavirus COVID-19 are being considered in the world. The article proposes a resonant approach to the detection of coronavirus COVID-19. Next, consider the vibrational practice of detecting and neutralizing COVID-19.

\section{Vibration Practice of Detecting and Neutralizing} Covid-19

Like any other virus, (COVID-19) is a low vibrational entity with a closed structure of an electromagnetic biofield. The resonance frequency of the biofield from $2 \mathrm{Hertz}$ is up to 7 Hertz. If you set the electromagnetic frequency above the base value, the virus dies. It is not active in high ranges. Starting from the ranges of $25.5 \mathrm{Hertz}$ and above, the virus dies. The virus in nature, outside the body, is not upright, since the total average frequency resonance of the Earth today is 27.4 Hertz. People filling hospitals, metro and public electric transport, shopping centers, offices, drinking establishments, prisons form the vibrations of the biofield below 7 Hertz, where COVID-19 retains its existence.

Low-frequency mental states maintain COVID-19 activity:

1. grief gives vibrations - from 0.1 to 2 Hertz;

2. fear - from 0.2 to $2.2 \mathrm{Hertz}$;

3. offense - from 0.6 to 3.3 Hertz;

4. irritation - from 0.9 to Hertz;

5. disturbance - from 0.6 to $1.9 \mathrm{Hertz}$;

6. temper-0.9 Hertz;

7. outbreak of rage - 0.5 Hertz;

8. anger - 1.4 Hertz;

9. pride $-0.8 \mathrm{Hertz}$;

10. neglect - 1.5 Hertz;

11. superiority - 1.9 Hertz;

High-frequency mental states suppress COVID-19 activity:

1. generosity - $95 \mathrm{Hertz}$;

2. gratitude - 45 Hertz;

3. heartfelt gratitude - from 140 Hertz and above;

4. sense of unity with other people - 144 Hertz and above;

5. compassion - from 150 Hertz and above;

6. love as a good, bright feeling - 50 Hertz;

7. love that man generates with his heart for all people and all living things without exception - from 150 Hertz and above;

8. unconditional, sacrificial, spiritual love - from 205 Hertz and above.

This is confirmed by Gilmutdinova Flyura Gaptraufovna, candidate of medical sciences, assistant of the Department of Clinical Physiology and Non-Pharmaceutical Methods of Therapy of the Faculty of Advanced Training of Medical Workers (FPKMR) of the Medical Institute (MI) of the Russian 
University of Friendship of Peoples (RUDN), Moscow. Everyone knows that by small but periodic influences, even a massive and durable system can be destroyed. For this, it is often enough that the frequency of external exposure and the natural frequency of the system coincide. Laser pulses of a certain frequency, coinciding with the intrinsic frequency of the virus envelope, can kill some of them. Determining this frequency is often a difficult task, and the effect of a laser of another frequency can even be harmed. Experimenters are based on experience and try to predict what frequency the virus can kill. And if they manage to choose the parameters of the impact, then they often succeed. Japanese scientists Otto Sankey and his colleague Eric Dykeman have developed a technique for determining the frequency of virus envelope vibration. Using a similar model, it is possible to make a microresonator with the frequency necessary to affect a given virus.

\section{Detection Of Coronavirus Covid-19 In The Body By Resonance Method}

The human population was superimposed with COVID 19 coronavirus. Every day more than 200 thousand people are infected in the world per day. The rapid detection of coronavirus in every person on the planet earth is a pressing problem. Research Center NATURAL INFORMATICS develops the project to detect coronavirus COVID-19 in the body by resonance method. The development represents KnowHow. Detection of coronavirus COVID-19 in an organism, it is possible to carry out the microdevice consisting of a chip of detection of coronavirus in an organism on the basis of a resonance at its own frequency of electromagnetic waves of the biofield, and from the notification microprocessor about a disease of the citizen to the network medical platform. Technologists are able to manufacture optical microresonators with high accuracy. The size error of the microresonators is less than the diameter of the hydrogen atom [1]. The ability to obtain microresonators with an accuracy of 0.17 angstroms allows you to create more complex optical circuits and solve the problem of using them to detect coronovirus. This value is 100 times smaller than the nanometer. Such a significant leap in microresonator production technologies increases their efficiency [2].

The design of the micro-device is in the form of an amulet. A technologically effective micro-device for detecting coronovirus COVID-19 in the body can ensure the complete safety of the appearance of infected people in places of mass accumulation of people throughout the world through the international medical platform of the World Health Organization. The micro-device for detecting coronovirus COVID-19 in the body can be used in all objects of mass accumulation of people and in all points of the world in open and closed areas and premises. At the time of acquisition of the micro-device, the owner is assigned its number in the network medical platform. It will be necessary to legislate the mandatory wearing by citizens in places of mass accumulation of people of a micro-device for detecting coronavirus. The microarray is designed in the form of an amulet and worn from the chest at the level of the thymus gland. Proposed resonant method of coronavirus detection COVID-19 promotes its effective neutralization and does not spread in places of mass accumulation of people.

\section{Spiritual Needs And Balanced Psyche From Stress And} Infection Covid-19

Dr. Robert Becker measured the brain waves of mentally balanced people. All of them had the same frequencies $-8 \mathrm{~Hz}$, synchronized by Schumann waves in frequency and phase. Professor Winfried Otto Schumann of the Munich Technical University established waves of ultra-small frequencies of 8 $\mathrm{Hz}$ between the earth and the ionosphere. The intensity of Schumann's resonance positively affects the mental state of a person according to experiments of scientists.

We live longer, but we feel worse. Medicine is poorly guided by spiritual principles and health criteria. Human life has a spiritual nature that is the cornerstone of health. It helps to achieve and maintain human health on a global scale. A person maintains a healthy state with a spiritual life, an ethical word, good intentions, spiritual connections with society. Japanese scientist Masaru Emoto, showed that water under the influence of our thoughts, emotions, words changes structure. The experiments of Masaru Emoto proved that the spiritual word has a healthy effect on a person.

According to international research by scientists such as Professor Winfried Otto Schumann, Dr. Robert Becker and Masaru Emoto, it follows that human health is balanced by a psychophysiological state with the body functioning at the electromagnetic frequency of 8 hertz cells in resonance mode [3]. The psyche of a person is very closely related to his needs. Personality needs are a source of psyche activity. The activity of the psyche is manifested in the process of satisfying human needs. Satisfaction is a positive mental state. Constant satisfaction is the state and the main indicator of a balanced psyche. Experimental tests and social surveys show that people satisfied with the realization of the necessary material and cultural needs have a balanced psyche. Long - term satisfaction contributes to a balanced psyche.

Needs are deeply linked to worldview and value systems. The value system focuses the individual on a particular strategy of life behavior. The value system is a

Citation: Evgeny Bryndin*, Resonance Method of Detection and Neutralization of Covid-19. Op Acc J Bio Sci \& Res 4(5)-2020. 
collection of human assessments of objects and phenomena of the world around us - it directly indicates how to relate to existing needs, how to shape and correct them. Value is the assessment of phenomena and events as good or evil, useful or harmful, beautiful or ugly, preoccupied or forbidden, just or unjust, etc. The possibility of comparing the surrounding world with the needs and values of man with brilliant accuracy is found in the aphorism of the ancient Greek sophist Protagoras (c. 490 - c. 420 BC): "Man is In this statement, the value approach to the world is clearly manifested.

Needs and values permeate literally all spheres of public life, all social structures and relations. Requirements and values act as an important link between society, the social environment and the individual, the personality, her inner world.

Values are people's beliefs about life and acceptable behavior. Moral value is taking responsibility for your actions. Spiritual values, love, truth, good and beauty are the values of the spiritual life of the person. Spirituality - there is an internal attitude of the individual to act according to his conscience. The spiritual life of society is unthinkable without combining spiritual production and spiritual consumption. No one can enjoy music that is not created! In the spiritual life of society, activities aimed at the creation, preservation and dissemination of spiritual values, spiritual needs and spiritual consumption are inextricable unity. Spiritual consumption is a special type of activity and, therefore, it has its focus, requires certain efforts, the use of appropriate means. In the process of spiritual consumption, the means of achieving the goal are, on the one hand, material opportunities, on the other hand, appropriate knowledge and skills (in order to read the book, you need to be able to get it in the library or buy it.) The level of education and the general culture of the individual directly affects the consumption of spiritual values.

The spiritual needs of man are internal motives for creativity, the creation of spiritual values and their development, for spiritual communication. Spiritual needs are set socially. In itself, this need does not arise. It must be formed and developed by the social context, the environment of the individual in the complex and long process of his upbringing and education. At the same time, at first, society forms in a person only the most elementary spiritual needs that ensure its socialization. The spiritual needs of a higher order - the development of the riches of world culture, participation in their creation, etc. - society can form only indirectly, through a system of spiritual values, serving as guidelines in the spiritual self-development of individuals.
Spiritual needs are fundamentally unlimited. There are no limits to the growth of spirit needs. The natural limitations of such growth can be only the volume of spiritual wealth already accumulated by mankind, the ability and strength of a person's desire to participate in their production.

Spiritual activity is the basis of the spiritual life of man and society. Spiritual activity reflects ideas, images, ideas, values embodied in philosophical systems, scientific theories, works of art, moral and religious views. As well as the spiritual social ties of individuals and the person himself. Products of spiritual activity and production have a universal nature of their consumption. Any spiritual value can ideally be the property of all. From consumption, they do not diminish as material, on the contrary, the more people master spiritual values, the more likely they are to increase. A special type of spiritual activity is the dissemination of spiritual values in order to absorb them by as many people as possible. A special role here belongs to the institutions of science, culture, the church, education and education systems.

Spiritual values are a category that indicates the human, social and cultural significance of various spiritual ideas, theories, images considered in the context of "good and evil," "truth or lies," "beautiful or ugly," "just or unjust." Spiritual values express the social nature of man himself and the conditions of his existence. Man is a spiritual being, part of the spiritual world created by God. A person with the ability to experience spiritual needs more accurately and better perceives the world around him in all his diversity. Such a person more easily and quickly understands that behavior coinciding with the norms of morality, among other things, gives a feeling of emotional satisfaction and inner calm, makes the psyche balanced [4-11]. It easily tolerates stress in the conditions of the coronavirus pandemic COVID-19 and retains a healthy state [12-14].

\section{Conclusion}

A vibrational approach to the rapid detection and neutralization of coronavirus is a universal and large-scale method that can reach all mankind and help avoid infections and the spread of COVID-19. A healthy spiritual lifestyle that accumulates positive mental energy helps resist the infection with coronavirus COVID-19. Parade of planets in December 2019 initiated a pandemic COVID-19 vibration impact. Parade of planets in early July 2020 will activate a new wave of coronavirus infections. Statistics of COVID-19 diseases in different countries of the world on July 15, 2020 confirm its activity with a total number of infections - 225552. In some countries, the epidemic is gaining momentum: USA - 67028, Brazil - 41857, India - 29429, South Africa - 10496, 
Mexico - 7051. On July 17, 2020, the number of infections in the world reached 237,743 , and on July 19,2020 is equal to 259,848 new infections and 7,360 deaths.

The main source of infection with coronavirus is bats. Bats are carriers of many diseases dangerous to humans. They themselves do not suffer from these infections, because they are able to raise body temperature, thereby activating the immune system. Doctors warn that bats can infect a person with Ebola, SARS, Marburg virus, hemorrhagic fever, rabies, coronavirus and other pathologies. Bat excrement is infected with histoplasmosis. The litter of bats exudes fumes that penetrate the human body. Litter pairs can lead to the development of serious pathologies of the respiratory system.

Virologist Jonathan Latham and biologist Allison Wilson found notes from a doctor who in 2012 treated miners from the Chinese province of Yunnan. The notes describe how workers cleaned the mine from bat feces for two weeks, and then fell ill with a strange disease. The patients showed symptoms characteristic of COVID-19: high fever, dry cough and pain in the limbs. Patients were treated almost the same as those now treated with coronavirus - with the help of anticoagulants, antibiotics and ventilators. As a result, three of the six workers died. Tests of patients were then sent to a laboratory in Wuhan. It turned out that the miners contracted a coronavirus similar to atypical pneumonia.

Bats are in all countries. Over many years, winds and rains have spread bat excrement across the planet. They are a global source of human coronavirus infection. That is, they are the source of the pandemic. The allocation of funds for the sanitary treatment of bat clusters will save humanity from infection with coronavirus for many years. Now it is important to find all forms of coronavirus in public places in order to effectively combat it and neutralize it. For example, to detect the crystalline form of the existence of coronavirus and, if possible, other immunological forms. Mankind leads to nature, resources and the living earth as barbarians. According to spiritual laws, it deservedly received a coronavirus for its deeds. If mankind does not build a moral spiritual way of life, nature will attack it with disasters. If humanity does not restore the environment and provide sanitation to public places, nature will attack it with coronaviruses.

\section{References}

1. Toropov NA, Sumetsky M (2016) Permanent matching of coupled optical bottle resonators with better than $0.16 \mathrm{GHz}$ precision. Optics Letters 41(10): pp. 2278-2281.

2. Evgeniy Bryndin (2020) Transformation Modeling of Nanostructures by Cognitive Systems according to Big Smart Data. Chepter 3, Pages: 21-28. / Book "New Materials: Preparation, Properties and Applications in the Aspect of Nanotechnology". USA: Nova Science Publisher pp. 250.

3. Bryndin EG, Bryndina IE (2019) Hygiene and Endoecology, Light Bioenergy and Natural Ecology, Balanced Mentality and Spiritual Life as Criterion of Health. Innovative Journal of Medical and Health Science 9(2): 299-306.

4. Evgeniy Bryndin, Irina Bryndina (2019) Natural Science Approach to Determination of Health and Formation of Healthy Lifestyle. ACTA SCIENTIFIC MEDICAL SCIENCES JOURNAL 3(1): 26-37.

5. Bryndin EG, Putmakov AN (2019) Frequency color visualization of a condition of the person according to spectral analysis of biofield and biodiagnostics. Journal of Medical Practice and Review 3(4): 505-509.

6. Evgeniy Bryndin, Irina Bryndina (2019) Development of Health Care on Basis of Healthy Lifestyle for Forming Future Medicine of Longevity. Acta Scientific Medical Sciences 3(5): 35-41.

7. Bryndin Evgeniy Grigorevich, Bryndina Irina Evgenievna (2019) International Public Health Care on Basis Healthy Lifestyle. Asian Journal of Medical Science Research \& Review 2(1): 88-96.

8. Evgeniy Bryndin, Irina Bryndina (2019) Supporting Technology of Vigorous Activity by Normalization of Biofield and by Healthy Lifestyle. International Journal of Healthcare and Medical Sciences 5(2): 1-11.

9. Evgeniy Bryndin, Irina Bryndina (2019) Technological Diagnostics of Human Condition According to Spectral Analysis of Biofield. Advances in Bioscience and Bioengineering 7(3): 64-68.

10. Evgeniy Bryndin, Irina Bryndina (2019) Normalization of Psyche of the Motivated Population by Healthy Lifestyle. Lupine Online Journal Medical Sciences 4(2): 364-367.

11. Evgeniy Bryndin (2020) Self Healing of Healthy Condition at Cellular Level. Medical Case Reports and Reviews, London 3: Pages: 1-4.

12. Bryndin E, Bryndina I (2019) Training of Healthy Lifestyle in Educational Schools. Asclepius Medical Case Reports 2(1): 1-3.

13. Evgeniy Bryndin, Irina Bryndina (2020) Countries have Accumulated Experience in Combating COVID 19 to Build System of Effective Neutralization. Clinical Case Reports: Open Access 3(3): P. 1-7.

14. Evgeniy Bryndin (2018) Satisfaction with valuable realization of requirements by spiritual personality counterbalances psyche. MOJ Public Health 7(6): 254-257.

\footnotetext{
*Corresponding author: : Evgeny Bryndin, Email: bryndin15@yandex.ru

Next Submission with BGSR follows:

- Rapid Peer Review

- Reprints for Original Copy

- $\quad$ E-Prints Availability

- Below URL for auxiliary Submission Link: https://biogenericpublishers.com/submit-manuscript/
}

Citation: Evgeny Bryndin*, Resonance Method of Detection and Neutralization of Covid-19. Op Acc J Bio Sci \& Res 4(5)-2020. 